\title{
Analysis of wave heights and wind speeds in the Adriatic Sea
}

\author{
M. Katalinić \\ Faculty of Maritime Studies, University of Split, Split, Croatia \\ M. Ćorak \& J. Parunov \\ Faculty of Mechanical Engineering and Naval Architecture, University of Zagreb, Zagreb, Croatia
}

\begin{abstract}
The study aims to determine mean annual wave heights and wind speeds in the Adriatic Sea. The Adriatic serves as a shipping route towards central Europe and a food and energy source for surrounding countries. Wave and wind climate information can serve as basis for design, research and policy making regarding ship safety and operability, potential renewable energy exploitation, design of off-shore installation etc. Mean annual wave height and wind speed values have been statically derived based on 43,274 ship sea state observations reported by the Hydrographical Institute of Republic of Croatia. This data has been digitalized and processed resulting in mean annual observed wave heights and corresponding wind speed values. Calm sea and no wind time percent periods have been calculated and wind-speedto-wave-height correlations presented. The obtained results are discussed for accuracy, significant effects are listed and future work guidelines are given.
\end{abstract}

\section{INTRODUCTION}

Thorough knowledge about possible sea states in a certain area is essential for all activities related to the maritime sector (e.g. offshore installations, ship design for safety and seakeeping, shipping routes planning, vessel management etc.). Every increase in knowledge in this field for the Adriatic basin is important as it serves as a busy shipping route with an increasing trend. Sea state analyses are available from in-situ measurement data, numerical modelling, and various forecast models derived on empirical or mathematical models giving relations between wind and waves. The present study aims to contribute to the field by further developing the statistical analysis of the data available from a collection of numerous ship observations of wind and wave states throughout the Adriatic. It aims primarily to identify mean annual wave heights for the whole Adriatic basin, and to look in more detail the zone of maximum wave heights (and subsequently energy), researching its relation to the dominant winds. Such an analysis can serve as a data source for possible wave energy evaluation projects in the region, or give the input design parameters for vessels designed for that specific basin.

\section{WIND WAVE CLIMATE OF THE ADRIATIC}

The Adriatic Sea climate is greatly determined by its position and surrounding topography. It is a part of the Mediterranean Sea, located in its north, central, part and interconnected to it by the Strait of Otranto on the south east side. For the major part the Adriatic Sea is categorized as the Mediterranean climate type (sub type Csa-Mediterranean climate with dry and hot summers, Favro \& Saganic, 2007).

The surface of the Adriatic Sea reads 138,595 sq. $\mathrm{km}$, or $4.6 \%$ of the Mediterranean Sea area. It is of elongated, rectangular shape, stretching from the north-west to the south-east, between the Dinaric and Apennine mountain ranges that influence the dominant winds and consequent wave patterns. Surface wind waves in the Adriatic are limited by fetch and wind duration. Average width, across the Adriatic, from the north-east to the southwest is about $200 \mathrm{~km}$. Furthermore, there are more than 1300 islands along the east coast that locally change the wind and wave characteristics. Sea depths are of such scale that cannot be neglected in the greater part of the basin. The shallowest area is in the north, in the Gulf of Trieste, and deepest is in the South-Adriatic pit (1233 m). Overall, more than $2 / 3$ of the Adriatic basin is not deeper than 200 meters (Pilot book for boats, 2002).

Dominant wind events that cause surface waves are bura (N-NE to E-NE, italian bora) and jugo (E-SE to SS-E, sirocco family) in the winter and maestral (W-NW to NW) in the summer (Favro \& Saganic, 2007). Bura and jugo reach storm conditions and can cause extreme wave occurrences while meastral is of milder character. Maximum recorded wave in the Adriatic was during an event 


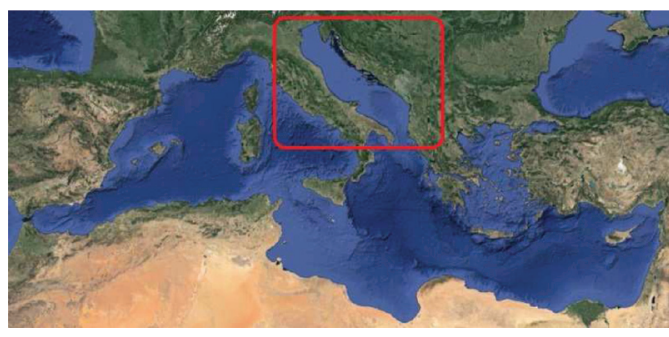

Figure 1. Adriatic Sea. Source: Google maps.

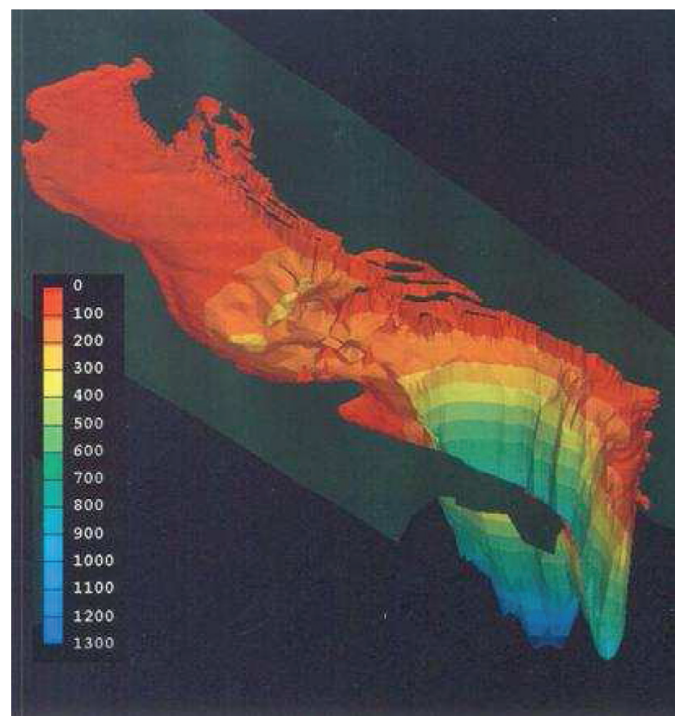

Figure 2. Adriatic bathymetry. Source: http://engineering. dartmouth.edu/adriatic/index.html.

of jugo wind with a wave height of 10.8 meters. Theoretical predictions of most probable extreme significant wave heights given by Leder et al. (1998) for 20 and 100 year return periods are 7.20 and 8.57 meters respectively. During bura wind events maximum wave height that can occur are between 6.2 and 7.2 meters (Pilot book for boats, 2002). Other important winds that cause surface waves are ostro $(\mathrm{S})$, lebeccio, garbin $(\mathrm{SW})$, ponent $(\mathrm{W})$, tramontane $(\mathrm{N}$ to $\mathrm{NW})$, levante $(\mathrm{E})$, and coastal circulation winds (burin or land-breeze and zmorac or sea-breeze).

Bura (N-NE to E-NE) is the strongest wind by intensity. It blows over the Dinaric Mountains which shape its focus points. By nature it blows in gales up to $20 \mathrm{~m} / \mathrm{s}(72 \mathrm{~km} / \mathrm{h})$ of velocity and can exceed $50 \mathrm{~m} / \mathrm{s}(180 \mathrm{~km} / \mathrm{h})$. The fastest recorded wind impact of bura is $68 \mathrm{~m} / \mathrm{s}(245 \mathrm{~km} / \mathrm{h})$ in the mid-Adriatic coast line where the Velebit Mountain forms a funnel. The main limitation for development of bura wind waves is the relatively narrow fetch across the Adriatic, especially if considered between the outer islands on the east coast until the west coast.

Jugo blows along the Adriatic (E-SE to SS-E) and usually develops up for two to three days until reaching its maximum speed. Waves, already formed, enter through the Otranto Strait southern boundary and develop further along the Adriatic reaching a more developed sea state and longer waves than those of bura which are inherently stepper and shorter. In storm conditions jugo can reach a speed up to $30 \mathrm{~m} / \mathrm{s}$ (over $100 \mathrm{~km} / \mathrm{h}$ ).

Force 6 (according to the Beaufort scale) or stronger wind blows along the coast 25 to 40 days a year, while force 8 or stronger wind blows 2 to 10 days a year. Extreme wind events that occur several times per year last from 1 to 17 hours (Parunov et al. 2011). These events carry large amounts of energy which is transformed into surface waves in a limited proportion due to wind duration and fetch limitations. It can be stated that, in general, due to the inability for the waves to fully develop before reaching one of the boundaries of the basin they remain shorter and steeper than would their ocean counterparts. Zorovic et al. (2003) studied and confirmed these relations and gave an expression linking wave length and height for the Adriatic basin:

$$
\lambda=16.78 H^{0.71}
$$

where $\lambda$ is the wavelength; $H$ is wave height.

The specific nature of the Adriatic Sea wave spectrum was studied and given by Tabain (1997) in a form of a one-parameter wave spectrum.

$$
S_{\eta}=0.862 \frac{0.0135 g^{2}}{\omega^{5}} e^{\left[-\left(\frac{5.186}{\omega^{4} H_{S}^{2}}\right)\right]} 1.63^{p}
$$

where

$$
\begin{array}{ll}
p=e^{\left[-\left(\left(\omega-\omega_{m}\right)^{2} / 2 \sigma^{2} \omega_{m}^{2}\right)\right]} ; \quad \omega_{m}=0.32+\frac{1.8}{H_{S}+0.60} \\
\sigma=0.08 f \text { or } \omega \leq \omega_{m} ; \quad \sigma=0.1 f \text { or } \omega \geq \omega_{m}
\end{array}
$$

\section{DESCRIPTION OF OBSERVATION DATA}

Wave data acquired by ship observations has been collected and made available from the Hydrographical Institute of Republic of Croatia. The data is published in a graphical form of "wave roses" in their publication, Climatology Atlas (1979), which also contains information about 


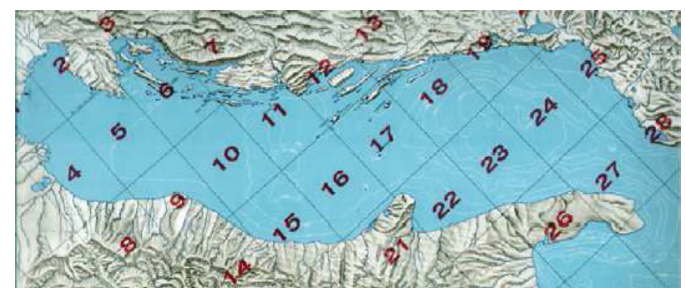

Figure 3. Spatial division $\left(1^{\circ}\right.$ by $1^{\circ}$ wave zones).

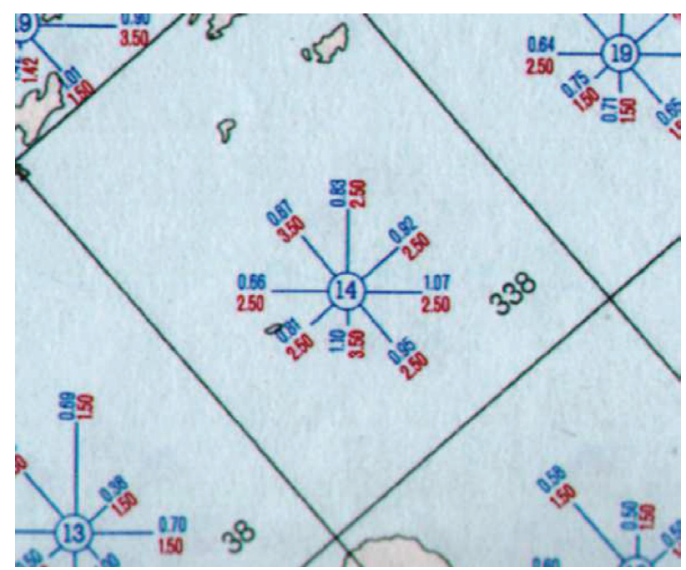

Figure 4. "Wave rose" example-zone 17.

wind, precipitation, temperatures etc. The wave and wind data collected by merchant and research ships in the period from 1957 to 1971, with a total of 43,274 complete metrological observations served as a basis for this study.

The data is presented by "wave roses" on a monthly basis, in a spatial resolution of $1^{\circ}$ latitude by $1^{\circ}$ longitude wave zones, with the whole Adriatic basin being divided in 28 of these zones.

Each wave zone contains information about monthly average frequencies of observed wave heights from a particular direction. In each wave zone the total number of observations is specified in the bottom left corner of each zone, while the number in the centre of the "wave rose" represents the percentage of calm sea states observed. The upper numbers on the directional bars present average monthly significant wave heights and the lower numbers present the maximum wave height ever observed from a particular direction. The lengths of the bars represent the relative number of waves coming from direction of the bar.
Wave data in this form have been digitalized and further statistically analysed as well as the related wind data given by the Climatology Atlas.

\section{WAVE HEIGHT AND WIND SPEED DISTRIBUTION}

Initially, mean annual significant wave heights have been derived from the digitalized data and their results are presented in Figure 5.

It can be noted that the highest mean annual wave heights are encountered in zones $24,25,27$ and 28 i.e. on the southern boundary of the Adriatic Sea, close to the Otranto Strait. These zones correlate with the highest mean annual wind speeds which are presented in Figure 6.

The southern Adriatic boundary is under the influence of winds and wind waves arriving from the central Mediterranean which explains the highest values found in adjacent zones.

The following figures, Figure 7 and Figure 8, show time percentage without wind and waves (too small to be noticed or measured) respectively, per quadrants, on an annual level.

The least percentage of time with no wind and with calm sea conditions (no waves) is again observed in quadrants 24, 25, 27 and 28.

From the above listed zones, zone 25 has the highest mean annual wave heights and the highest annual wind speed and is therefore further analysed.

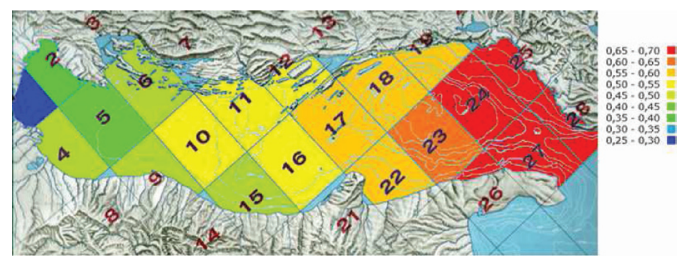

Figure 5. Mean annul significant wave heights per quadrant in the Adriatic Sea [m].

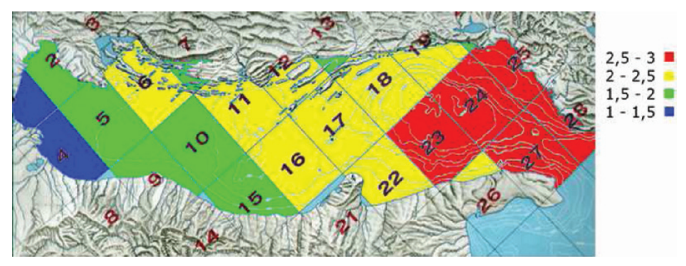

Figure 6. Mean annual wind speeds per quadrant in the Adriatic Sea [Bf]. 


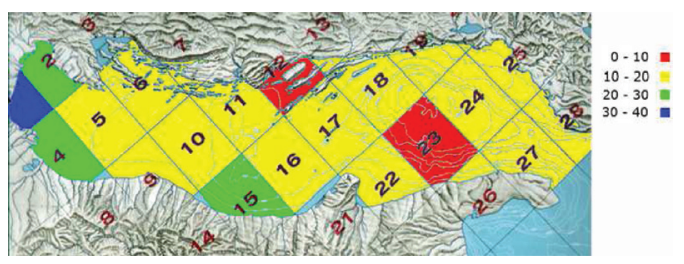

Figure 7. Time percentage with no wind in the Adriatic Sea.

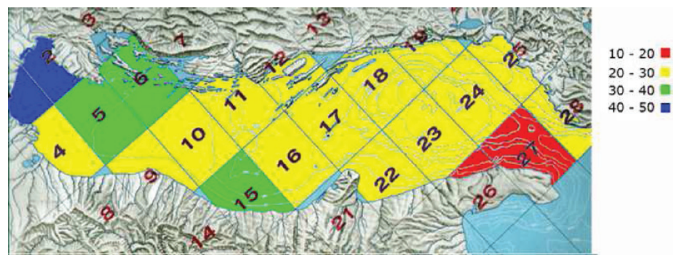

Figure 8. Time percentage of calm seas in the Adriatic Sea $[\%]$.

\section{ZONE 25 DETAIL ANALYSIS}

Statistical analysis results of wave heights and wind speeds for the zone 25 are presented in Table 1 and Table 2.

Data given in Table 1 and 2 shows mean annual values. Relations between wind speed and wave height correspond well to the standard Beaufort scale, e.g. wind of $3 \mathrm{Bf}$ relates to a wave height of about 0.6 meters.

Figure 9 gives the distribution and correlation of mean wave heights and wind speed throughout the year for the zone 25 .

The wave height pattern relates well to the wind speed pattern. It can also be noticed from the figure that both wind speeds and wave heights reach lower values during summer months (5-9). During winter months higher wind speeds and higher wave heights occur, especially for months 1-3 (Jan-Mar).

Figure 10 shows the relation between mean significant wave height and mean wind speed for each month throughout the year for zone 25 with a quadratic trendline derived. Quadratic dependence was found to be best suited, especially for higher wind speeds. A parabolic relation of wind-speed to wave-height is expected and known in literature. It should be noted though, that wind speed is expressed on the Beaufort scale.

Finally, Figure 11 and Figure 12, show polar plots for mean annual significant wave height and wind speeds to show directional dependency of the observed values for zone 25 .
Table 1. Mean annual significant wave height—zone 25 .

\begin{tabular}{lllll}
\hline $\begin{array}{l}\text { Percentage of calm seas } \\
\text { No. of wave observations }\end{array}$ & $\begin{array}{l}23 \\
236\end{array}$ & & \\
\hline Direction & $\begin{array}{l}\text { Mean } \\
\text { values } \\
\text { of waves }\end{array}$ & $\begin{array}{l}\text { Max } \\
\text { value } \\
\text { m }\end{array}$ & $\begin{array}{l}\text { Freq. } \\
\%\end{array}$ & $\begin{array}{l}\text { No. of } \\
\text { waves } \\
-\end{array}$ \\
\hline N & 0.95 & 1.75 & 6 & 16 \\
NE & 0.84 & 1.55 & 19 & 48 \\
E & 0.89 & 1.67 & 9 & 21 \\
SE & 1.30 & 1.70 & 8 & 21 \\
S & 0.89 & 1.68 & 11 & 25 \\
SW & 1.00 & 1.56 & 8 & 20 \\
W & 0.73 & 1.22 & 7 & 15 \\
NW & 0.65 & 1.50 & 9 & 20 \\
\hline
\end{tabular}

Table 2. Mean annual wind speed-zone 25 .

\begin{tabular}{lll}
\hline $\begin{array}{l}\text { Percentage of no wind } \\
\text { No. of wind observations }\end{array}$ & $\begin{array}{l}12 \\
319\end{array}$ \\
\hline Direction of wind & $\begin{array}{l}\text { Mean values } \\
\text { Bf }\end{array}$ & $\begin{array}{l}\text { Frequencies } \\
\%\end{array}$ \\
\hline N & 4.14 & 5 \\
NE & 3.55 & 20 \\
E & 3.11 & 13 \\
SE & 3.56 & 11 \\
S & 3.36 & 11 \\
SW & 2.57 & 7 \\
W & 2.16 & 6 \\
NW & 2.09 & 15 \\
\hline
\end{tabular}

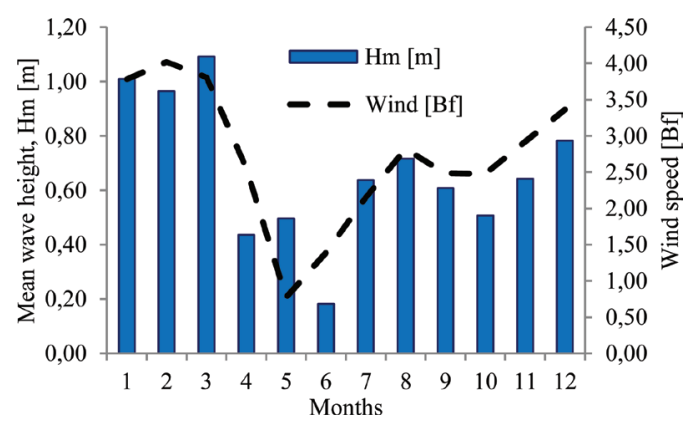

Figure 9. Mean wave height vs. mean wind speed correlation. 


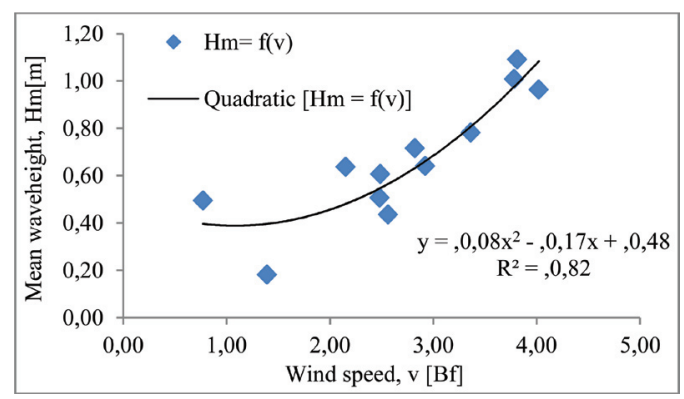

Figure 10. Wind speed to wave height relation.

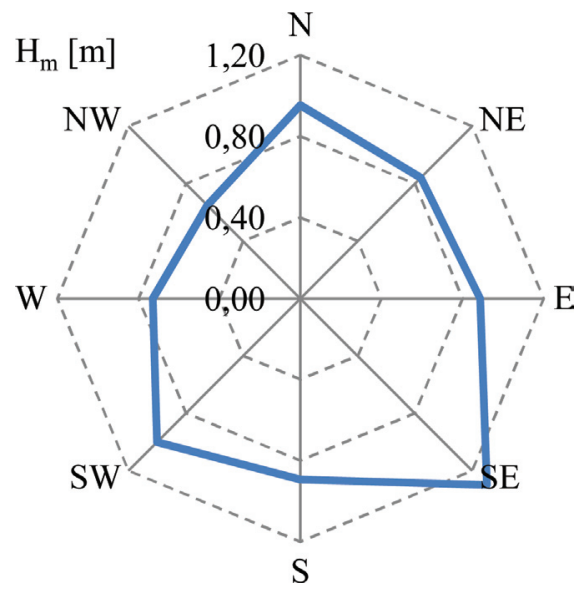

Figure 11. Mean annual wave height polar plot-zone 25.

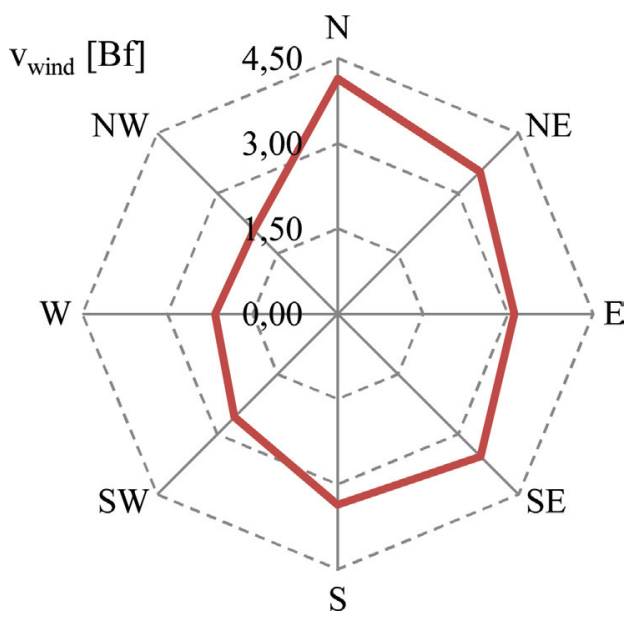

Figure 12. Mean annual wind speed polar plot-zone 25.

\section{DISCUSSION}

A difference in "overlapping" between wave height and wind speed directional values is pronounced in the SE quadrant, the direction from which waves enter from the Mediterranean through the southern boundary. This confirms that jugo wind (SE) is not the strongest wind, but it generates the largest waves. It blows for a longer period of time on a longer fetch. Moreover, as jugo wind-waves reach a more developed sea state, these waves should persist longer on the sea surface than less developed, steeper waves that tend to diminish more quickly. These findings are in line with those found in the reviewed literature. From the wind polar plot it can be noticed that the strongest winds are recorded from the direction of bura wind (N-NE). Wind forces of bura are even more emphasized due to the fact that it blows very strong for relatively short periods of time which increases its mean values.

Overall, the results are un-conservative with respect to the maximum values recorder and evaluated during extreme wind events in the literature. The un-conservative nature of the analysis based on observational data can result from two reasons. First, due to the bias in measurement values or theoretically derived values versus observational data noted by seafarers who are prone to underestimate the sea state (Guedes Soares 1986). The second reason can be found in the basic logic of maritime conduct, where prudent masters seek to avoid stormy conditions. Sea states with significant wave height over 4 meters in the Adriatic Sea are short lasting and usually correspond to wind of storm category, and thus there is lack of data of such observations.

Future work on waves in the Adriatic Sea is planned by implementation of SWAN, a numerical wave model, for the Adriatic basin. SWAN (Simulation Waves Near-Shore) is an open-source third generation wave model developed to compute random, short-crested wind-generated waves in coastal regions and inland waters. It resolves a wave action density spectrum balance equation that accounts for the following effects: wave propagation in time and space, shoaling, refraction due to current and depth, frequency shifting due to currents and nonstationary depth, wave generation by wind, triple and quadruple wave interaction, white-capping, bottom friction and depth induced breaking, dissipation due to vegetation, and diffraction. A full description of the SWAN model is given by Holthuijsen et al. (1989), Booij et al. (1999) and Ris et al. (1999). For the Adriatic Sea the model was tested by Jankovic \& Tudor (2005) for a single bura event and validated against data measured by a buoy located in the north Adriatic. The model showed accurate prediction. 
Implementation and validation of a numerical wave model can be used for hindcast and forecast analysis, wave energy evaluation, offshore installation design, forensic analysis of marine accidents etc. An adaptive model to forecast and evaluate the sea states would be important considering the possible climate changes induced by global warming.

\section{CONCLUSION}

Wave and wind observation data, published by the Hydrographical Institute of Republic of Croatia, collected from 43,274 ship metrological observations ('57-'71) were digitalized and statistically analysed to acquire mean annual wave height and wind speeds in space for the Adriatic Sea. It is found that wind speeds and wave heights increases from the northern part of the Adriatic basin towards the south. Maximum mean annual significant wave height obtained is 0.68 meters. The result is an underestimation compared with satellite altimetry measurement (Queffeulou \& Bentamy 2007) that reported mean significant wave height of 0.85 meters for a 14 year period (satellite missions during the 1992-2005 period). It also stated that $80 \%$ of the significant wave height data in the Adriatic Sea are less than 1.10 meters.

Zone 25 is analysed in detail deriving wind to wave relation throughout the year showing generally good correspondence. Directional analysis in the zone showed a discrepancy in a form of a wave height increase that is not noted in the wind speed values that can be interpreted as the waves entering from the Mediterranean Sea through the Otranto Strait.

Due to the un-conservative nature of the results it is not suggested to use the data for all types of design purposes where their miss-application could result in a safety issue, but should be applied where the nature of the application is aligned with the data that served as a base for this study. Consequently, the acquired results can be used for seakeeping design purposes and wave energy extraction design and planning.

\section{ACKNOWLEDGMENTS}

The authors would like to thank the students of the Faculty of Mechanical Engineering and Naval Architecture, University of Zagreb: Filip Aralica,
Marko Čakširan, Antonio Filipović, Nenad Kosanović, Luka Olrom; who contributed to the making of this paper with their hard work and enthusiasm.

This work has been supported in part by Croatian Science Foundation under the project 8658.

\section{REFERENCES}

Bertotti L., Cavaleri L., (2009), Wind and wave predictions in the Adriatic Sea, Journal of Marine Systems, 78, 227-234.

Favro S., Saganić I., (2007); Prirodna obilježja hrvatskog litoralnog prostora kao komparativna prednost za razvoj nautičkog turizma, Geoadria vol.12 No.1; 59-81.

Holthuijsen L.H., N. Booji, T.H.S. Herbers, 1989: A prediction model for stationary, short-crested waves in shallow water with ambient currents, Coastal Engineering Journal, 13, 23-54.

Hydrographic Institute of Republic of Croatia, 1979. Atlas of the Climatology of the Adriatic Sea.

Hydrographical Institute of Republic of Croatia, 2002, Pilot book for boats, ISBN 953-6165-25-2.

Janeković I., Tudor M., 2005, The Adriatic Sea wave response to severe Bura wind, Croatian Meteorological Journal, Vol. 40, 316-319.

Leder N., Smirčić A., Vilibić I., 1998. Extreme values of surface wave heights in the Northern Adriatic. Geofizika 15, 1-13.

Parunov J., Čorak M., Pensa M., 2011, Wave height statistics for seakeeping assessment of ships in the Adriatic Sea, Ocean Engineering, 38, 1323-1330.

Queffeulou, P., Bentamy, A., 2007. Analysis of wave height variability using altimeter measurements: application to the Mediterranean Sea. Journal of Atmospheric and Oceanic Technology 24 (12), 2078-2092.

Ris R.C., Booji N., Holthuijsen L.H. 1999: A thirdgeneration wave model for coastal regions. Part II Verification. Journal of Geophysical Research, 104, 7667-7681.

Rusu E., 2009, Wave energy assessments in the Black sea, Journal of Marine Science and Technology, 14, 359-372.

Rusu E., Guedes Soares C., 2008, Wave energy assessments in the coastal environment of Portugal continental, ASME 2008 27th International Conference on Offshore Mechanics and Arctic Engineering, 761-772.

Tabain, T., 1997. Standard wind wave spectrum for the Adriatic Sea revisited. Brodogradnja 45 (4), 303-313.

Zorović D., Mohović R., Mohović Đ. 2003, Towards determining the length of the wind waves in the Adriatic Sea., Naše more, 50 (3-4), 145-150. 